\title{
Mechanical Circulatory Support for Acute Right Ventricular Failure in the Setting of Pulmonary Embolism
}

\section{Authors:}

Mahir Elder, MD ${ }^{1}$, Nimrod Blank, MD ${ }^{1}$, Amir Kaki, MD ${ }^{1}, \mathrm{M}_{\text {Chadi Alraies }}{ }^{1}$ Cindy L. Grines ${ }^{2}$, MD, Marvin Kajy, $\mathrm{MD}^{1}$, Reema Hasan, $\mathrm{MD}^{3}$, Tamam Mohamad, $\mathrm{MD}^{1}$; Theodore Schreiber, $\mathrm{MD}^{1}$.

\section{Affiliation:}

${ }^{1}$ Wayne State University School of Medicine, Detroit Medical Center Heart Hospital, Detroit, MI.

${ }^{2}$ Zucker School of Medicine at Hofstra Northwell Health, Northshore University Hospital, Manhasset NY

${ }^{3}$ University of Michigan, Ann Arbor, MI

This is the author manuscript accepted for publication and has undergone full peer review but has not been through the copyediting, typesetting, pagination and proofreading process, which may lead to differences between this version and the Version of Record. Please cite this article as doi:

10.1111/joic.12503

This article is protected by copyright. All rights reserved 
Disclosure: None

Keywords: Mechanical circulatory support, right ventricle failure, cardiogenic shock, pulmonary embolism, Impella RP

Word count: 3511 .

Corresponding author: M Chadi Alraies, MD. Detroit Medical Center, Cardiovascular Institute, 311 Mack Ave. Detroit, Michigan. 48201. Phone : (216) 255-0008, email: alraies@ hotmail.com

\begin{abstract}
Background: Right ventricular (RV) failure due to pulmonary embolism (PE) increases morbidity and mortality and contributes to prolonged hospital length of stay and higher costs of care. RV mechanical circulatory support (MCS) including Impella RP devices have been increasingly used in hemodynamically compromised PE patients who are refractory to intravascular volume expansion and inotropic therapy. However, effectiveness and safety of Impella RP, in hemodynamically unstable PE patients is unknown.
\end{abstract}

Methods: We included consecutive patients who presented to Detroit Medical Center between November 3, 2015 and October 2, 2017 with acute PE and had evidence of hemodynamic compromise indicating Impella RP.

This article is protected by copyright. All rights reserved 
Results: Total of 5 cases were identified. All patients met the shock definition due to massive or submassive PE and therefore received Impella RP on admission. Cardiac index was improved from mean of $1.69 / \mathrm{min} / \mathrm{m}^{2},\left(0.88-2.15 \mathrm{l} / \mathrm{min} / \mathrm{m}^{2}\right.$ ), to $2.51 / \mathrm{min} / \mathrm{m}^{2}$ (range $1.88-3.4$ ), after 24 hours of treatment. Similarly, mean heart rate reduced to 92 beats per minute (79-105), and mean systolic blood pressure increased to $140 \mathrm{mmHg}$ (115-179). No significant changes were found in renal function, hemoglobin and platelets level during device use. One patient experienced hemoglobin drop from 13.7 to $7.3 \mathrm{~g} / \mathrm{dl}$ but didn't require blood transfusion. All patients survived to discharge.

Conclusion: In patients with PE and RV shock, Impella RP device resulted in immediate hemodynamic benefit with reversal of shock and favorable survival to discharge. 


\section{Introduction:}

Pulmonary embolism (PE) continues to be challenging both in diagnosis and management and accounts for more than 275,000 hospital admissions per year in the United States with associated mortality which is $15 \%$ within the first 3 months of presentation. ${ }^{1-4}$ In patients presenting with hemodynamically stable PE, treatment with systemic anticoagulation leads to case-fatality rates of approximately $2 \% .^{5-7}$ However, approximately $5 \%$ of patients with acute PE who develop hemodynamic instability, mortality can be as high as $20-50 \% .^{8}$

Evidence of RV failure measured by strain from transthoracic echocardiography, or CT-scan, enhance prediction of clinical deterioration after PE. ${ }^{8-10}$ Nevertheless, normotensive patients with RV dysfunction represented $30-40 \%$ of patients presenting with PE, of those, $10 \%$ develop PErelated shock after admission. ${ }^{9}$ This indicates that substantial latent hemodynamic impairment among patients with PE.

Multiple studies focused on strategies to risk-stratify patients with acute PE and guide use of potentially effective adjunctive therapies such as thrombolytics. Similarly, RV mechanical circulatory support (MCS) devices have been increasingly used in hemodynamically compromised patients who are refractory to intravascular volume expansion and inotropic therapy. ${ }^{11}$

The safety and efficacy of Impella RP (Abiomed, Danvers, MA) in patients with RVF has been studied in RECOVER RIGHT study, a prospective, open label, non-randomized multicenter trial, and showed both safety and efficacy in patients with RVF after left ventricular assist device (LVAD) and acute myocardial infarction. ${ }^{12}$ However, effectiveness and safety of Impella RP, in hemodynamically unstable PE patients is unknown.

This article is protected by copyright. All rights reserved 


\title{
Method and Materials:
}

\author{
Study population
}

We included consecutive patients who presented to Detroit Medical Center between November 3, 2015 and October 2, 2017 with acute PE and had evidence of hemodynamic compromise indicating Impella RP. Patient received Impella RP if the diagnosis of massive or submassive PE was confirmed. Based on the currently available guidelines, massive PE is defined as acute PE with sustained hypotension (systolic blood pressure $<90 \mathrm{~mm} \mathrm{Hg}$ for at least 15 minutes despite optimal medical treatment of intra vascular volume expansion with repeated normal saline $0.9 \%$ boluses, or refractory hypotension despite inotropic therapy, not due to a cause other than PE (i.e. arrhythmia, hypovolemia, sepsis, or LV dysfunction), pulselessness, or persistent profound bradycardia (heart rate $<40 \mathrm{bpm}$ with signs or symptoms of shock). ${ }^{10,13}$ While submassive PE is defined as acute PE without systemic hypotension (systolic blood pressure $>90 \mathrm{~mm} \mathrm{Hg}$ ) but with either RV dysfunction or myocardial necrosis. ${ }^{14}$ All patients were monitored with repeated echocardiography exams to assess RV size and function, continuous hemodynamic monitoring with a pulmonary artery catheter and invasive blood pressure monitoring.

\section{Data acquisition}

Demographics, baseline clinical characteristics, pre-implantation clinical course, and postimplantation outcomes were obtained from the medical record. Risk stratification using Pulmonary Embolism Severity Index (PESI) and simplified PESI (sPESI) scores were done for all patients prior to Impella RP in order to support the clinical indication for MCS (table 1). ${ }^{15,16}$ 
The pulmonary artery pulsatility index (PAPi) is a novel index to detect RV failure in myocardial infarction (MI) involving the RV. PAPI value $<0.9$ showed good correlation with mortality or the need for RV mechanical circulatory support for refractory RV failure. ${ }^{15}$ PAPI $<2$ predicts right side heart failure after left ventricular assist device (LVAD) implantation. ${ }^{11,16}$ The value of PAPI in the prediction of mortality or the requirement of RV mechanical circulatory support in PE patients has not been validated. PAPi score has been calculated for all five patients.

\section{Mechanical Circulatory Support}

The Impella Right Peripheral (RP) was used in all cases. Impella RP is a temporary right ventricular assist device (RVAD) that provides mechanical circulatory support to the right ventricle. Impella RP is a 3-dimensional catheter-based microaxial pump designed specifically for temporary RV support. In 2012, Abiomed's Impella RP was approved by the FDA for temporary mechanical circulatory support for cardiogenic shock due to RV failure in the setting of LV assist device (LVAD), myocardial infarction, heart transplant, or open-heart surgery. ${ }^{17}$

The device consists of 22 Fr pump head containing the electric motor, axial blood pump, and outflow cannula, mounted on an $11 \mathrm{~F}$ catheter. It is placed percutaneously through the femoral vein and advanced in an antegrade fashion across the pulmonic valve into the pulmonary artery under fluoroscopic guidance. The inflow portion of the catheter resides in the inferior vena cava, and a flexible nitinol cannula traverses the right atrium, tricuspid valve, and pulmonic valve. The outflow portion of the catheter resides in the main pulmonary artery. The device can supply perfusion of up to $4.4 \mathrm{~L} / \mathrm{min}$ for an anticipated duration of up to 14 days. The pump is inserted through a right heart catheterization procedure via the femoral vein, and requires a $23 \mathrm{Fr}$ sheath introducer. After advancing the right heart catheter into the level of the pulmonary artery, a guide wire is advanced This article is protected by copyright. All rights reserved 
to the level of the left pulmonary artery. The Impella RP device is advanced over the guide wire to its position. The guide wire is removed and the device then secured and activated. Anticoagulation is always recommended while Impella RP is used to prevent clotting. Heparin is already in the Impella purge solution and supplemental intravenous heparin was administered to maintain activated clotting time (ACT) between 200-250 seconds. Impella RP weaning was facilitated through the use of several parameters evaluating the hemodynamic stability which include; improved systolic BP without inotropic support, improved cardiac index, and improved urine output to $>0.5 \mathrm{ml} / \mathrm{kg} / \mathrm{min}$. Once hemodynamic stability is achieved, gradual power and output was decreased. Once the patients remained hemodynamically stable for several hours with minimal mechanical circulatory support, the patients were deemed ready for device removal. Once the device was removed, surgical closing sutures, mattress suture or figure of eight suture techniques with manual compression was used to achieve hemostasis.

\section{Catheter-Directed Ultrasound-Accelerated Thrombolysis}

The EKOS EkoSonic ${ }^{\circledR}$ Endovascular system (EkoSonic Endovascular System, EKOS Corporation; Bothell; WA) delivers low-intensity ultrasound for the purpose of facilitated thrombolysis using low-dose fibrinolytic therapy. ${ }^{18}$ The ultrasound disaggregates fibrin strands, increases permeability of the clot, and disperses the fibrinolytic drug into clot through acoustic microstreaming effects. The EkoSonic Endovascular System includes an Intelligent Drug Delivery Catheter (IDDC), MicroSonic Device (MSD) containing a series of miniature ultrasound transducers positioned along the treatment zone, and a Control Unit. The IDDC is a 5.2Fr multilumen sideport infusion catheter, with infusion lengths ranging from 6 to $50 \mathrm{~cm}$, which accommodates the coaxial 0.035 " MSD to deliver uniform radial ultrasound energy ( $2.2 \mathrm{MHz})$ to 
the entire infusion zone with simultaneous rt-PA infusion. The Control Unit continuously monitors treatment zone temperature measured by the IDDC's thermocouples and automatically adjusts delivered ultrasound power to optimize thrombolysis. The EkoSonic System has been approved by the US FDA for the infusion of solutions into the pulmonary arteries in April 2008.

\section{Results}

Five patients with PE complicated with hemodynamic instability and cardiogenic shock were treated with Impella RP due to acute RV failure. Preoperative patient characteristics are reported in (table 2). One patient presented with cardiogenic shock on admission whereas the other four presented with submassive PE which was complicated with shock after admission. Three out of the five patients had saddle emboli. Two patients experienced massive PE that extend from the main pulmonary artery into five branches as seen on CT angiography and pulmonary angiogram (figure 1 and 2). All patients were screened for deep vein thrombosis (DVT) before device insertion. One patient was diagnosed with DVT in the right femoral and popliteal veins below the level of the common femoral vein and thus did not preclude from device insertion through the right femoral vein. One patient was diagnosed with DVT in the left femoral and popliteal veins. Three patients had now DVT. All patients were treated with IV heparin for anticoagulation with bolus dose of 5,000 units and maintenance dose adjusted to patient weight with routine monitoring of ACT to target of 200-250 seconds.

Echocardiogram was performed for all five patients prior to Impella RP insertion. Using 4chamber view, fractional area change, and tricuspid annular plane systolic excursion (TAPSE). Based on these measurements, all five patients had remarkable RV dilation with moderate to severe 
dysfunction prior to Impella RP insertion. The LV ejection fraction was preserved in all five patients and (>50\%) (Table 3).

Risk stratification using PESI and sPESI scores indicated high risk of 30-day mortality in all patients (mean PESI 101 and mean sPESI 7.3) (table 4). Using the right heart catheterization numbers before Impella RP insertion, mean PAPi was 1.6, despite marked RV dilation and function abnormalities on echocardiography (table 4). Mean pulmonary artery pressure was 43 $\mathrm{mmHg}$ as measured during initial right heart catheterization (range of 33-57 $\mathrm{mmHg}$ ) (table 5).

The mean time for Impella RP support was 3.2 days (range of 1 to 6 days). Prior to device insertion systolic blood pressure ranged from 85 to $127 \mathrm{mmHg}$. For patients with systolic blood pressure $>90 \mathrm{mmHg}$, the systolic blood pressure dropped by $40 \mathrm{mmHg}$ of more from baseline which met the shock definition. Also, the mean heart rate was 114 beats per minutes (ranging from 94 to 145 beat per minute) on presentation indicating the hemodynamic instability of these patients. Invasive hemodynamic assessment and all patients had right heart catheterization before Impella RP device was inserted (Table 5). Cardiac index (CI) was low indicating cardiogenic shock on presentation with mean CI of $1.69 \mathrm{l} / \mathrm{min} / \mathrm{m}^{2}$ (range $0.88-2.15 \mathrm{l} / \mathrm{min} / \mathrm{m}^{2}$ ) (table 5). Based on echocardiogram that was done on admission as well, all patients had preserved LV function with ejection fraction $>50 \%$ which ruled out LV dysfunction as mechanism for cardiac shock.

Patients received treatment with catheter-directed ultrasound-accelerated thrombolysis (CDUAT) using the EKOS EkoSonic ${ }^{\circledR}$ Endovascular system. The use of CDUAT was based on the operator discretion. Two patients received two systems based on the operator assessment of the pulmonary angiogram that showed heavy clot burden (table 4). Length of thrombolysis therapy varied between 6-12 hours. Alteplase $5 \mathrm{mg}$ was administered as bolus treatment during device This article is protected by copyright. All rights reserved 
deployment, followed by infusion at a rate of $2 \mathrm{mg} /$ hour for 4 hours then $1 \mathrm{mg} /$ hour for the remaining time.

With Impella RP treatment, all patients showed significant clinical and hemodynamic improvement. Mean heart rate reduced to 92 beats per minute (79-105), and mean systolic blood pressure increased to $140 \mathrm{mmHg}$ (115-179). Similarly, cardiac index increased from $1.69 \mathrm{l} / \mathrm{min} / \mathrm{m}^{2}$ $(0.88-2.15)$ to $2.50 \mathrm{1} / \mathrm{min} / \mathrm{m}^{2}(1.95-3.40)$ immediately after initiation of Impella RP. Echocardiogram at 3 days following Impella RP showed improvement in RV function, TAPSE, and FAC (table 3).

The length of mechanical circulatory support use was 1 day for two patients 3,5 and 6 days for the other patients. There is no standardized protocol for device weaning and explantation. Device explantation was done when the patients were off inotropic support, free of sepsis and with stable hemodynamics with minimal support. Echocardiogram findings that suggested RV recovery was another parameter that we used to wean MCS.

Overall, all patients showed stable hemodynamics that continued after Impella RP MCS removal. All patients also, were successfully discharged from index admission and had 100\% one month follow-up survival.

\section{Safety endpoint}

No change in renal function, hemoglobin, or platelet level was noted at the end of Impella RP MCS support. One patient, treated with Impella RP for 6 days, had a fall in hemoglobin levels from 13.7 $\mathrm{g} / \mathrm{dl}$ to a nadir of $7.30 \mathrm{~g} / \mathrm{dl}$. No patients received packed red blood cell transfusion during Impella RP treatment and all patients were successfully discharged from the hospital. One patient required This article is protected by copyright. All rights reserved 
treatment with milrinone $0.75 \mathrm{mcg} / \mathrm{kg} / \mathrm{min}$ for 48 hours and sildenafil $20 \mathrm{mg}$ TID for residual severe pulmonary hypertension that was continued to discharge. One patient developed enterococcus faecalis bacteremia and septic shock required short term inotropic support with norepinephrine.

\section{Discussion:}

This study demonstrates the rapid reversal of right ventricular failure among patients with massive and submassive PE who were treated with Impella RP. The device appeared to be associated with a favorable side effect profile. This case series provides the first demonstration of the feasibility and clinical effects of a mechanical circulatory support to rapidly improve RV dysfunction in patients with acute PE.

Beside systemic thrombolysis therapy for patients presenting with massive PE with shock, catheter-directed therapy is regarded as safer alternative due to reported lower rates of major bleeding and hemorrhagic complications. ${ }^{10,19}$ This method is now indicated for massive and submassive PE patients to reduce immediate and long-term complications. ${ }^{20}$ In order to further decrease the dose of thrombolytics and decrease bleeding complications, catheter-directed ultrasound-accelerated thrombolysis (CDUAT) has emerged which decreased the dose of thrombolytics and also increased clot penetration. ${ }^{18,21}$ Although these technologies showed decreased clot burden for patients with acute PE and shock, they lack mechanical support for failing RV. Furthermore, no study has been done to show improvement in invasive hemodynamics using CDUAT.

\footnotetext{
This article is protected by copyright. All rights reserved
} 
The current guideline recommends fluids boluses as the first step for acute RV failure with emphasis to avoid excessive volume overload which may result in extreme RV dilatation and a precipitous decline in RV performance ${ }^{22}$. Second-line management includes inotropic support to increase RV cardiac output by increasing RV contractility and heart rate. ${ }^{23}$ Patients refractory to those treatments, RV support with MCS has been suggested as a "bridging" intervention for faster recovery. ${ }^{24} \mathrm{RV}$ acute MCS now represents an important step in the management of RV failure and provides an opportunity to rapidly stabilize patients with cardiogenic shock involving the RV. Several iterations of surgical RVAD has been developed but continue to require large-bore cannulas, anticoagulation and sternotomy or thoracotomy. These limitations led to the development of percutaneous MCS devices, including Impella RP that allows for early intervention in RV failure without the need for surgery. ${ }^{12,25}$ However, the effectiveness of this device for use in acute RV failure has not been demonstrated in patients with acute submassive or massive PE accompanied with RV-mediated cardiogenic shock.

Our findings support the utility of MCS using Impella RP in patients presenting with massive PE accompanied with RV-mediated cardiogenic shock. All patients in our series received guideline based treatment with anticoagulation, volume expansion, inotropic support and catheter-mediated thrombolysis. Also, all patients received CDUAT using EkoSonic Endovascular System. Despite following guideline-directed management, patients continued to be in shock as indicated with invasive hemodynamics as well as echocardiogram findings that suggested severe RV dilatation and dysfunction. All patients

Despite low number of cases, the results of the present study are comparable to the previous studies, demonstrating successful device explantation and survival to discharge in all cases. ${ }^{25}$ 
Importantly, we have also shown that all patients exhibit normal RV function after device explantation. This is better to what other studies have shown of partial (15\%) improvement in RV failure after device explantation. This suggests that RV functional recovery may continue over the first year after device explantation. Based on these findings, we recommend using continuous pulmonary arterial pressure monitoring routinely for patient with RV failure treated with MCS devices, preferably dual lumen Swan-Ganz catheter. This approach will provide continuous right atrial and pulmonary pressures which will provide further guidance for hemodynamic support using MCS.

We have described the clinical outcomes of patients with acute RV failure due to acute PE supported with the Impella RP. Our findings suggest that implantation of these devices is clinically feasible, associated with acute hemodynamic improvement, and facilitate successful bridge-torecovery in most patients.

\section{Limitations:}

Although the current case series showed favorable outcome, these results should be interpreted with caution given the retrospective data collection, small sample size that may not be very representative of the patient population. Although not all patient had invasive hemodynamic assessment at the end of the case, our echocardiogram assessment showed evidence of RV recovery which could be used as surrogate marker for improved cardiac output. Also, the decision to use Impella RP was solely based on operator discretion with lack of standardized protocol which could inherently affect the results of the study. This may undermine the external validity of the current findings and therefore definitive recommendations cannot be made. Therefore, larger studies with control group is needed to confirm the favorable results.

This article is protected by copyright. All rights reserved 


\section{Conclusion:}

In patients with PE and RV shock, Impella RP device resulted in immediate hemodynamic benefit with reversal of shock and favorable survival to discharge. These findings support its probable benefit in this gravely ill patient population.

This article is protected by copyright. All rights reserved 


\section{Figure legends:}

Figure 1: CT angiography showing massive pulmonary embolism involving the right and left main pulmonary arteries (arrows).

Figure 2: Pulmonary angiography shows pulmonary embolism with bilateral oligemia more prominent on the right side (arrow).

Figure 3: Impella RP positioned across the pulmonic valve. The inlet is at the inferior vena cava (IVC) and right atrium junction (arrow) and outlet is into the main pulmonary artery (arrow head).

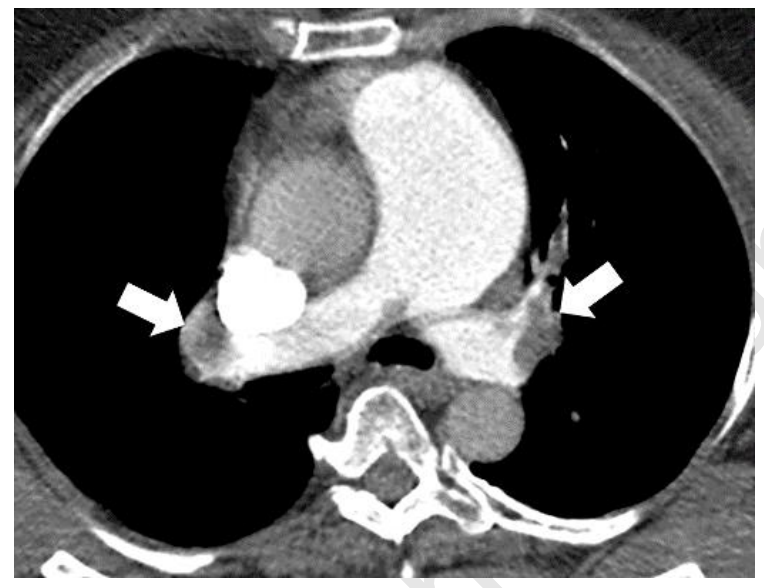

Figure 1 


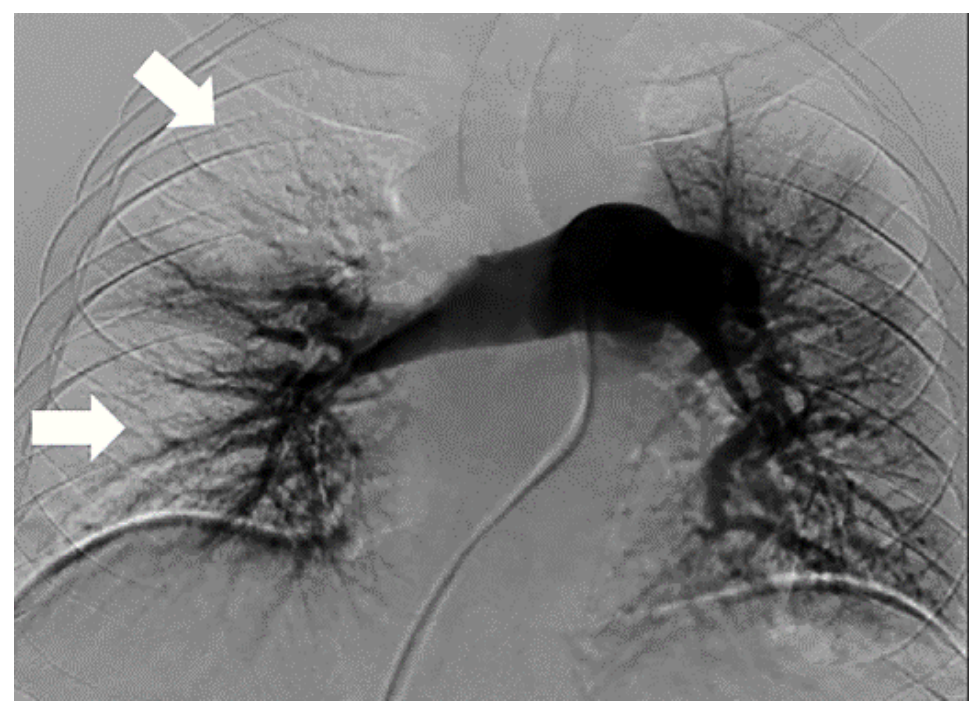

Figure 2

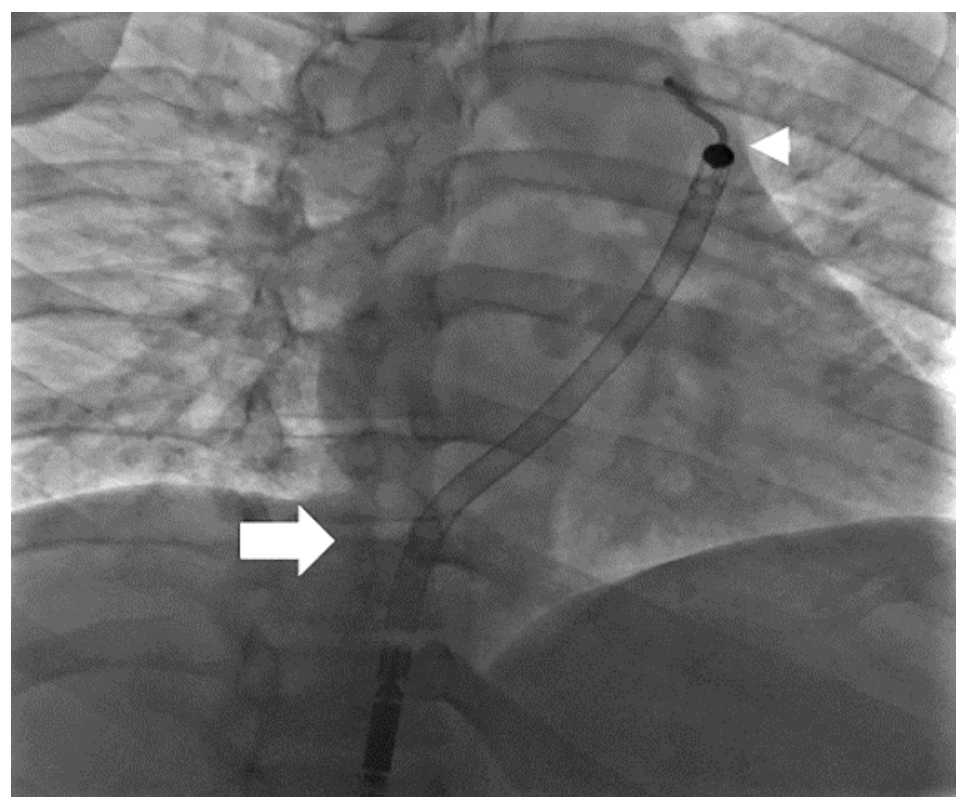

Figure 3

This article is protected by copyright. All rights reserved 


\section{References:}

1. Moser KM, Fedullo PF, LitteJohn JK, Crawford R. Frequent asymptomatic pulmonary embolism in patients with deep venous thrombosis. Jama. 1994;271(3):223-225.

2. Oger E. Incidence of venous thromboembolism: a community-based study in Western France. EPI-GETBP Study Group. Groupe d'Etude de la Thrombose de Bretagne Occidentale. Thrombosis and haemostasis. 2000;83(5):657-660.

3. Bĕlohlávek J, Dytrych V, Linhart A. Pulmonary embolism, part I: Epidemiology, risk factors and risk stratification, pathophysiology, clinical presentation, diagnosis and nonthrombotic pulmonary embolism. Experimental \& Clinical Cardiology. 2013;18(2):129.

4. Control CfD, Prevention. Venous thromboembolism in adult hospitalizations-United States, 2007-2009. MMWR Morbidity and mortality weekly report. 2012;61(22):401.

5. Douketis JD, Kearon C, Bates S, Duku EK, Ginsberg JS. Risk of fatal pulmonary embolism in patients with treated venous thromboembolism. Jama. 1998;279(6):458-462.

6. Kearon C, Akl EA, Comerota AJ, et al. Antithrombotic therapy for VTE disease. Chest. 2012;141(2 Suppl):e419S-e494S.

7. ten Wolde M, Söhne M, Quak E, Mac Gillavry MR, Büller HR. Prognostic value of echocardiographically assessed right ventricular dysfunction in patients with pulmonary embolism. Archives of internal medicine. 2004;164(15):1685-1689. 
8. Kucher N, Rossi E, De Rosa M, Goldhaber SZ. Massive pulmonary embolism. Circulation. 2006;113(4):577-582.

9. Grifoni S, Olivotto I, Cecchini P, et al. Short-term clinical outcome of patients with acute pulmonary embolism, normal blood pressure, and echocardiographic right ventricular dysfunction. Circulation. 2000;101(24):2817-2822.

10. Force M, Konstantinides S, Torbicki A, et al. ESC Guidelines on the diagnosis and management of acute pulmonary embolism: The Task Force for the Diagnosis and Management of Acute Pulmonary Embolism of the European Society of Cardiology (ESC) Endorsed by the European Respiratory Society (ERS). Eur Heart J. 2014;35:3033-3073.

11. Kapur NK, Esposito ML, Bader Y, et al. Mechanical Circulatory Support Devices for Acute Right Ventricular Failure. Circulation. 2017;136(3):314-326.

12. Anderson MB, Goldstein J, Milano C, et al. Benefits of a novel percutaneous ventricular assist device for right heart failure: The prospective RECOVER RIGHT study of the Impella RP device. J Heart Lung Transplant. 2015;34(12):1549-1560.

13. Goldhaber SZ, Visani L, De Rosa M. Acute pulmonary embolism: clinical outcomes in the International Cooperative Pulmonary Embolism Registry (ICOPER). The Lancet. 1999;353(9162):1386-1389.

14. Jaff MR, McMurtry MS, Archer SL, et al. Management of massive and submassive pulmonary embolism, iliofemoral deep vein thrombosis, and chronic thromboembolic pulmonary hypertension. Circulation. 2011;123(16):1788-1830.

This article is protected by copyright. All rights reserved 
15. Korabathina R, Heffernan KS, Paruchuri V, et al. The pulmonary artery pulsatility index identifies severe right ventricular dysfunction in acute inferior myocardial infarction. Catheterization and Cardiovascular Interventions. 2012;80(4):593-600.

16. Kang G, Ha R, Banerjee D. Pulmonary artery pulsatility index predicts right ventricular failure after left ventricular assist device implantation. The Journal of Heart and Lung Transplantation. 2016;35(1):67-73.

17. Abiomed Receives FDA HDE Approval for the Impella RP: First FDA Approved Percutaneous Single Access Heart Pump Designed for Right Heart Support. Abiomed. Published January 27 AF. In.

18. Engelhardt TC, Taylor AJ, Simprini LA, Kucher N. Catheter-directed ultrasoundaccelerated thrombolysis for the treatment of acute pulmonary embolism. Thrombosis research. 2011;128(2):149-154.

19. Konstantinides S, Goldhaber SZ. Pulmonary embolism: risk assessment and management. European heart journal. 2012;33(24):3014-3022.

20. U.S. Food and Drug Administration CfDEaREM-IS, August 6, 2007. Retrieved October 16, 2017, from https://www.accessdata.fda.gov/cdrh_docs/pdf6/k063620.pdf. In.

21. Piazza G, Hohlfelder B, Jaff MR, et al. A prospective, single-arm, multicenter trial of ultrasound-facilitated, catheter-directed, low-dose fibrinolysis for acute massive and submassive pulmonary embolism: the SEATTLE II study. JACC: Cardiovascular Interventions. 2015;8(10):1382-1392.

This article is protected by copyright. All rights reserved 
22. Mebazaa A, Yilmaz MB, Levy P, et al. Recommendations on pre-hospital \& early hospital management of acute heart failure: a consensus paper from the Heart Failure Association of the European Society of Cardiology, the European Society of Emergency Medicine and the Society of Academic Emergency Medicine. European journal of heart failure. 2015;17(6):544-558.

23. McMurray JJ, Adamopoulos S, Anker SD, et al. ESC Guidelines for the diagnosis and treatment of acute and chronic heart failure 2012. European journal of heart failure. 2012;14(8):803-869.

24. Goldstein JA, Kern MJ. Percutaneous mechanical support for the failing right heart. Cardiology clinics. 2012;30(2):303-310.

25. Cheung AW, White CW, Davis MK, Freed DH. Short-term mechanical circulatory support for recovery from acute right ventricular failure: clinical outcomes. The Journal of Heart and Lung Transplantation. 2014;33(8):794-799.

This article is protected by copyright. All rights reserved 
Table 1: Pulmonary Embolism Severity Index parameters and risk stratification

\begin{tabular}{|c|c|c|c|}
\hline Parameters & PESI & \multicolumn{2}{|c|}{ Simplified PESI } \\
\hline Age & Age in years & \multicolumn{2}{|c|}{1 point (if age $>80$ years) } \\
\hline Male sex & +10 points & \multicolumn{2}{|r|}{-} \\
\hline Cancer & +30 points & \multicolumn{2}{|r|}{1 point } \\
\hline $\mathrm{CHF}$ & +10 points & \multicolumn{2}{|r|}{1 point } \\
\hline Chronic pulmonary disease & +10 points & \multicolumn{2}{|r|}{1 point } \\
\hline Pulse rate $\geq 110$ b.p.m & & \multicolumn{2}{|r|}{1 point } \\
\hline $\mathrm{SBP}<100 \mathrm{mmHg}$ & +30 points & \multicolumn{2}{|r|}{1 point } \\
\hline Respiratory rate $>30$ per min & +20 points & \multicolumn{2}{|r|}{-} \\
\hline Temperature $<36^{\circ} \mathrm{C}$ & +20 points & \multicolumn{2}{|r|}{-} \\
\hline Altered mental status & +60 points & \multicolumn{2}{|r|}{-} \\
\hline \multirow[t]{5}{*}{ Arterial oxyhemoglobin saturation $<90 \%$} & +20 points & \multicolumn{2}{|r|}{1 point } \\
\hline & \multicolumn{3}{|c|}{ Risk stratification ${ }^{*}$} \\
\hline & Points & \multicolumn{2}{|c|}{ 30-day Mortality } \\
\hline & Class I & Very low & $0-1.6 \%$ \\
\hline & Class II $\quad 66-85$ & Low & $1.7-3.5 \%$ \\
\hline \multirow[t]{3}{*}{ PESI } & Class III 86-105 & Moderate & $3.2-7.1 \%$ \\
\hline & Class IV $\quad 106-125$ & High & $4.0-11.4 \%$ \\
\hline & Class V >125 & Very high & $10.0-24.5 \%$ \\
\hline \multirow{2}{*}{ Simplified PESI } & 0 & \multicolumn{2}{|r|}{$1.0 \%$} \\
\hline & $\geq 1$ & \multicolumn{2}{|r|}{$10.9 \%$} \\
\hline
\end{tabular}

This article is protected by copyright. All rights reserved 


\begin{tabular}{|c|c|c|c|c|c|c|c|c|c|c|c|c|c|}
\hline & Age & BSA & VTE history & Cancer history & $A C$ & CAD & ICD & HTN & DM & $\mathrm{HCL}$ & $\mathrm{Cr}$ & Hgb & Plt \\
\hline Patient 1 & 72 & 2.21 & PE in 2012 & No & No & No & No & YES & No & No & 1 & 14.8 & 157 \\
\hline Patient 2 & 28 & 2.21 & No & No & No & No & No & No & No & No & 1.32 & 14.2 & 215 \\
\hline Patient 3 & 52 & 2.23 & No & No & No & No & No & No & No & No & 1.09 & 8.1 & 220 \\
\hline
\end{tabular}

PE- pulmonary embolism, BSA - body mass index, VTE - venous thromboembolism, AC - anticoagulation, CAD - coronary artery disease, ICD Implantable Cardioverter Defibrillator, HTN - hypertension, DM - diabetes mellitus, $\mathrm{HCL}$ - hypercholesterolemia, $\mathrm{Cr}-\mathrm{creatinine}, \mathrm{Hgb}-\mathrm{hemoglobin}$, Plt - platelet 


\begin{tabular}{|c|c|c|c|c|c|c|}
\hline & \multicolumn{3}{|c|}{ DAY 0} & \multicolumn{3}{|c|}{ Before discontinuation of MCS } \\
\hline & RV A4C & FAC & TAPSE & RV A4C & FAC & TAPSE \\
\hline Patient 1 & 60 & 22 & 15 & 56 & 45 & 20 \\
\hline Patient 2 & 50 & 17 & 13 & 48 & 27 & 17 \\
\hline Patient 3 & & 9 & 16 & 60 & 23 & 17 \\
\hline Patient 4 & 53 & 11 & 12 & 46 & 23 & 13 \\
\hline Patient 5 & NA & NA & NA & NA & NA & NA \\
\hline \multicolumn{7}{|c|}{$\begin{array}{l}\text { Follow up shows improvement in RV size and function based in apical 4-chamber view, fractional area change and tricuspid } \\
\text { annular plane systolic excursion. Left ventricular ejection fraction was preserved in all patients (>50\%). Abbreviations: RV - } \\
\text { right ventricle, MCS - mechanical circulatory support, A4C - apical 4-chamber view, FAC - fractional area change, TAPSE - } \\
\text { Tricuspid annular plane systolic excursion, NA - not available. }\end{array}$} \\
\hline
\end{tabular}


Table 4: Vital signs and risk stratification before and after MCS with Impella RP.

\begin{tabular}{|c|c|c|c|c|c|c|c|c|c|c|c|c|}
\hline & \multirow{2}{*}{ Impella (days) } & \multirow{2}{*}{ Peak Trop } & \multirow{2}{*}{ Peak NT-proBNP } & \multirow{2}{*}{ EkoSonic } & \multirow{2}{*}{ PESI } & \multirow{2}{*}{ sPESI } & \multirow{2}{*}{ PAPI } & \multicolumn{2}{|c|}{ HR } & \multicolumn{3}{|c|}{ BP } \\
\hline & & & & & & & & Before & After & Admission & Before & After \\
\hline Patient 1 & 3 & 0.023 & 758 & 1 & 82 & 1.1 & 3.06 & 94 & 80 & $149 / 82$ & $91 / 59$ & $179 / 94$ \\
\hline Patient 2 & 1 & 0.092 & 5069 & 2 & 58 & 8.9 & 1.66 & 106 & 92 & $155 / 112$ & $99 / 69$ & $173 / 97$ \\
\hline Patient 3 & 6 & 0.434 & 8245 & 1 & 103 & 8.9 & 0.56 & 103 & 94 & $96 / 80$ & $86 / 71$ & $125 / 85$ \\
\hline Patient 4 & 5 & 6.166 & NA & 2 & 129 & 8.9 & 1.15 & 124 & 79 & $93 / 60$ & $87 / 56$ & $150 / 71$ \\
\hline Patient 5 & 1 & 0.06 & 1821 & 1 & 134 & 8.9 & 0.81 & 92 & 101 & $129 / 107$ & $138 / 97$ & $129 / 103$ \\
\hline $\begin{array}{l}\text { Risk stratifi } \\
\text { out of } 5 \text { pat } \\
\text { Trop - trop } \\
\text { Pulmonary }\end{array}$ & $\begin{array}{l}\text { tion using PESI sF } \\
\text { nts despite seere } \\
\text { nin (ng/L) , NT-pr } \\
\text { nbolism Severity }\end{array}$ & $\begin{array}{l}\text { PESI showed } \\
\text { e RV dilatatio } \\
\text { roBNP - N-te } \\
\text { Index, sPESI }\end{array}$ & $\begin{array}{l}\text { oderate to severe } \mathrm{m} \\
\text { and dysfunction on e } \\
\text { ninal pro-brain natri } \\
\text { simplified PESI, PAPI }\end{array}$ & $\begin{array}{l}\text { 730-days mo } \\
\text { echocardiog } \\
\text { iuretic pepti } \\
\text { I - pulmonar }\end{array}$ & $\begin{array}{l}\text { ality } \\
\mathrm{m}(\mathrm{PA} \\
\text { (pg) }\end{array}$ & $\begin{array}{l}\text { e refe } \\
\text { ore }<1 \\
\text { EkoSc }\end{array}$ & $\begin{array}{l}\text { ble } 1 \\
\text { ates R } \\
\text { Cathe }\end{array}$ & $\begin{array}{l}\text { PESI an } \\
\text { Abbrevi } \\
\text {-directe }\end{array}$ & $\begin{array}{l}\text { PESI SC } \\
\text { ons: MC } \\
\text { Itrasou }\end{array}$ & $\begin{array}{l}\text { e details). } P f \\
\text { - mechanic } \\
\text { d-accelerate } \\
\text { l pressure }\end{array}$ & $\begin{array}{l}\text { APi score } \\
\text { al circula } \\
\text { d thromb }\end{array}$ & $\begin{array}{l}\text { was low in } 2 \\
\text { ory support } \\
\text { olysis, PESI }\end{array}$ \\
\hline
\end{tabular}

Table 5. Right heart hemodynamics before and after treatment with MCS

\begin{tabular}{lcc|cc|ccc|c}
\hline & \multicolumn{2}{c}{ RA } & \multicolumn{2}{c|}{ RV } & \multicolumn{3}{c|}{ PA } & \multicolumn{2}{c}{ Cl } \\
\cline { 2 - 9 } Patient 1 & before & after & before & after & before & after & before & after \\
\cline { 2 - 9 } Patient 2 & $19 / 20 / 16$ & $22 / 21 / 26$ & $53 / 9 / 18$ & $71 / 15 / 23$ & $72 / 23 / 39$ & $62 / 34 / 44$ & 2 & $\mathrm{Na}$ \\
Patient 3 & $20 / 24 / 21$ & $\mathrm{Na}$ & $76 / 16 / 27$ & $\mathrm{Na}$ & $77 / 42 / 57$ & $\mathrm{Na}$ & 1.75 & $\mathrm{Na}$ \\
Patient 4 & $19 / 24 / 23$ & $\mathrm{Na}$ & $42 / 11 / 26$ & $\mathrm{Na}$ & $41 / 28 / 33$ & $\mathrm{Na}$ & 2.15 & $\mathrm{Na}$ \\
Patient 5 & $29 / 30 / 32$ & $19 / 19 / 18$ & $41 / 15 / 18$ & $\mathrm{Na}$ & $58 / 21 / 39$ & $57 / 31 / 40$ & 0.88 & 3.7 \\
\hline
\end{tabular}

Pressure values are described as systolic/diastolic/mean pressures. MCS - mechanical circulatory support, RA - right atrium pressure $(\mathrm{mmHg}), \mathrm{RV}$ - right ventricle pressure $(\mathrm{mmHg}), \mathrm{PA}$ - pulmonary pressure $(\mathrm{mmHg}), \mathrm{Cl}$ - cardiac index $\left(\mathrm{l} / \mathrm{min} / \mathrm{m}^{2}\right), \mathrm{NA}-$ not available 